William B. Kelly MD, Michael B. Howie MD, Vincent A. Romanelli MD, Jose A. Duarte MD, Hamid Rezaei Ms, Thomas D. McSweeney BS

\title{
A comparison of pentamorphone and fentanyl in balanced anaesthesia during general surgery
}

The purpose of our randomized, double-blind study of 64 unpremedicated healthy patients undergoing surgical procedures with a duration of at least $60 \mathrm{~min}$ was to compare $0.75 \mu \mathrm{g} \cdot \mathrm{kg}^{-1}$ and $1 \mu \mathrm{g} \cdot \mathrm{kg}^{-1}$ pentamorphone with $5 \mu \mathrm{g} \cdot \mathrm{kg}^{-l}$ and 7.5 $\mu \mathrm{g} \cdot \mathrm{kg}^{-1}$ fentanyl to determine which dose of opioid would reduce the requirement for isoflurane supplementation needed to maintain haemodynamic stability. At 21 points during the procedure, the haemodynamic variables of heart rate and systolic, diastolic, and mean arterial pressures were recorded. The use of isoflurane was quantified; the number of patients requiring inhaled anaesthetic, concentration peaks, MAC minutes, and duration of isoflurane use were noted. The number of equal-volume supplemental opioid analgesic doses, postoperative analgesics, occurrence of postoperative nausea, emesis, and antiemetic doses were compared. The four groups exhibited similar patient demographics, total dose of muscle relaxants, types of surgical procedures, and duration of surgery or anaesthesia. Haemodynamic variables were stable with no difference among the four study groups. The patients given pentamorphone demonstrated both delayed requirement $(P<0.05)$ and shorter duration $(P<0.05)$ of isoflurane supplementation. Patients given either $5 \mu \mathrm{g} \cdot \mathrm{kg}^{-1}$ or $7.5 \mu \mathrm{g} \cdot \mathrm{kg}^{-1}$ fentanyl needed isoflurane supplementation within $12 \pm 16 \mathrm{~min}$ and $12 \pm 17$ min from induction respectively; while patients given either 0.75 $\mu \mathrm{g} \cdot \mathrm{kg}^{-1}$ or $1 \mu \mathrm{g} \cdot \mathrm{kg}^{-1}$ pentamorphone did not require isoflurane supplementation for $37 \pm 10 \mathrm{~min}$ and $43 \pm 26 \mathrm{~min}$

\section{Key words}

ANAESTHETICS, INTRAVENOUS: fentanyl, pentamorphone; ANAESTHETICS, VOLATILE: isoflurane.

From the Department of Anesthesiology, Division of Cardiothoracic Anesthesia, Clinical Anesthesia Research Laboratory, The Ohio State University Medical Center, Doan Hall, Room N429, 410 West Tenth Avenue, Columbus, $\mathrm{OH}$ 43210-1228.

Supported in part by a grant from Anaquest Inc., Madison, WI.

Address correspondence to: Dr. William B. Kelly. Accepted for publication 30th April, 1994. respectively. In addition, the $1 \mathrm{\mu g} \cdot \mathrm{kg}^{-1}$ pentamorphone group had significantly $(P<0.05)$ lower peak isoflurane concentrations than the $5 \mu \mathrm{g} \cdot \mathrm{kg}^{-1}$ fentanyl study group $10.9 \pm 0.5$ $M A C \%$ vs $1.5 \pm 0.3 \mathrm{MAC \%}$ ). In conclusion, we found pentamorphone to be a haemodynamically stable, isofluranesparing opioid analgesic. Pentamorphone's major advantage over fentanyl was its lower requirement for inhalation agent in a balanced anaesthesia technique.

Cette étude randomisée et à double aveugle portait sur de 64 patients en bonne santé non prémédiqués soumis à des interventions diune durée minimale de $60 \mathrm{~min}$. Son objectif consistait à comparer $0.75 \mu \mathrm{g} \cdot \mathrm{kg}^{-1}$ et $1 \mathrm{\mu g} \cdot \mathrm{kg}^{-1}$ de pentamorphone avec $5 \mu \mathrm{g} \cdot \mathrm{kg}^{-1}$ et $7,5 \mu \mathrm{g} \cdot \mathrm{kg}^{-1}$ de fentanyl dans le but de déterminer la dose de morphinique capable de réduire le besoin de supplémentation à l'isoflurane nécessaire au maintien de la stabilité hémodynamique. A 21 étapes pendant lintervention, on enregistré les variables hémodynamiques représentées par la fréquence cardiaque et les pressions systoliques, diastoliques et moyennes. L'utilisation de lisoflurane est quantifiée de la façon suivante; le nombre de patients ayant besoin de l'agent inhalatoire, les concentrations maximales, le CAMminute et la durée d'utilisation. On compare le nombre de doses à volumes égaux de morphiniques en supplément, le besoin d'analgésiques postopératoires, l'occurrence des vomissements et des nausées postopératoires, ainsi que les doses d'antiémétiques. Les données démographiques, les doses totales de myorelaxants, le type d'intervention et la durée de l'anesthésie étaient les mêmes pour les quatre groupes. Les variables sont demeurées stables sans différences entre les quatre groupes. Les patients des groupes pentamorphone ont eu des besoins retardés $(P<0,05)$ et de plus courte durée $(P<0,05)$ disoflurane. Les patients recevant $5 \mu \mathrm{g} \cdot \mathrm{kg}^{-1}$ ou $7,5 \mu \mathrm{g} \cdot \mathrm{kg}^{-1}$ de fentanyl on eu besoin d'une supplémentation à l'isoflurane en deçà de $12 \pm 16$ min et $12 \pm 17$ min après línduction respectivement; par contre, les patients qui avaient reçu 0,75 $\mu \mathrm{g} \cdot \mathrm{kg}^{-1}$ ou $\mathrm{l} \mu \mathrm{g} \cdot \mathrm{kg}^{-1}$ de pentamorphone n'ont pas eu besoin de supplément d'isoflurane pendant $37 \pm 10$ min et $43 \pm 26$ min respectivement. De plus, le groupe pentamorphone 1 $\mu \mathrm{g} \cdot \mathrm{kg}^{-1}$ a reçu des concentrations isoflurane maximales moins 
élevées $(P<0,05)$ que le groupe fentanyl $5 \mu \mathrm{g} \cdot \mathrm{kg}^{-1}(0,9 \pm$ $0,5 \mathrm{MAC} \%$ versus $1,5 \pm 0,3 \mathrm{MAC} \%$ ). En conclusion nous avons trouvé que le pentamorphone procurait une bonne stabilité hémodynamique et réduisait les besoins disoflurane. Dans une technique anesthésique équilibrée, l'avantage majeur du pentamorphone sur le fentanyl réside dans sa capacité de diminuer le besoin d'agent inhalatoire.

The current most widely used opioid analgesic anaesthetics for general surgery are the piperidine derivatives sufentanil and fentanyl. Pentamorphone is an opioid that produces analgesia and sedation more rapidly than the closely related opioid analgesic, morphine. Several studies have described varying results as to the relative potency of pentamorphone compared with other opioids. An initial human volunteer study of pentamorphone using a calibrated spring rod indicated that it was 400 to 500 times as potent as morphine, with similar effects on blood pressure and heart rate. A second human volunteer study compared two doses of pentamorphone and fentanyl for analgesic tolerance to five noxious stimuli and determined an analgesic potency of pentamorphone at five times that of fentanyl. ${ }^{1}$ When administered postoperatively, pentamorphone in doses from 0.08 to $0.24 \mu \mathrm{g} \cdot \mathrm{kg}^{-1}$ were not sufficient to relieve acute postoperative pain after major abdominal or orthopaedic surgery when compared to a placebo. ${ }^{2,3}$ Another human volunteer study demonstrated that when pentamorphone was administered in increasing doses, it produced a linear increase in pain threshold as well as a concurrent respiratory depression, which was similar to other opioids. ${ }^{4} \mathrm{~A}$ patient controlled analgesia study placed the relative analgesic potency of pentamorphone at 170 times greater than morphine. ${ }^{5}$ Pentamorphone given as a constant infusion in very high doses in canines displayed slight, direct myocardial depressant effects on heart rate, mean arterial pressure and cardiac output. ${ }^{6}$ As the sole anaesthetic in patients undergoing elective coronary artery bypass grafting surgery, the time to loss of consciousness placed the relative analgesic potency of pentamorphone at five to six times greater than fentanyl. ${ }^{7}$ Animal studies have compared pentamorphone with fentanyl and report an analgesic potency of two to eight times greater than that of fentanyl. ${ }^{8}$ However, when large doses are given to a dog, pentamorphone has been shown to be epileptogenic. The study demonstrated myotomic activity at dose levels of $\geq 125 \mu \mathrm{g} \cdot \mathrm{kg}^{-1}$, with $E_{50}$ for analgesia in the same study at $12 \mu \mathrm{g} \cdot \mathrm{kg}^{-1}$. The seizure activity was demonstrated in a single animal monitored with EEG at a dose level of $350 \mu \mathrm{g} \cdot \mathrm{kg}^{-1}$ (unpublished data: in Anaquest Investigator's Brochure).

Pentamorphone, formerly designated RX77989 and A4492, is a synthetic opioid with strong analgesic effects

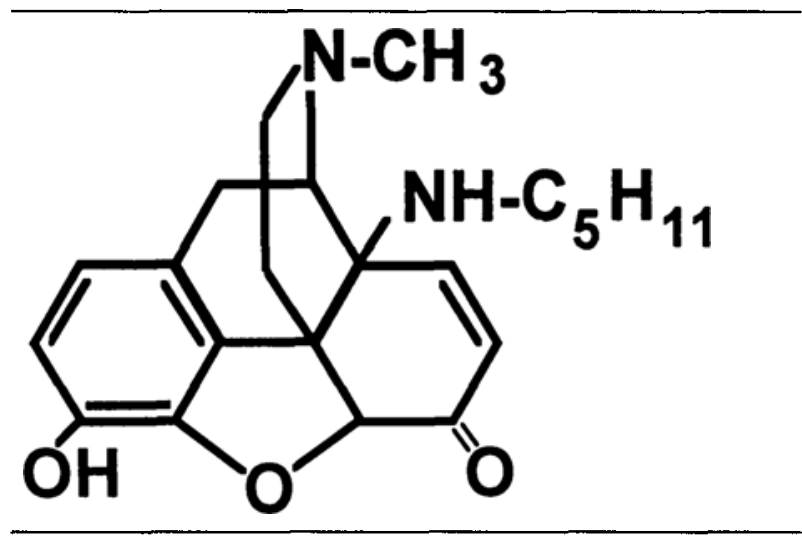

FIGURE 1 The chemical structure of pentamorphone [7,8didehydro-4,5-epoxy-3 hydroxy-17-methyl-14-(pentylamino)-(5)morphinan-6-one; Anaquest, Murray Hill, NJ is very similar to that of morphine.

and has demonstrated a lower degree of undesirable side effects in previous studies. Structurally (Figure 1), pentamorphone is a $14-\beta-n$-pentylaminomorphinone [IUOAC name 7,8-didehydro-4,5-epoxy-3 hydroxy-17methyl-14-(pentylamino)-(5)-morphinan-6-one]. Pentamorphone is a pale, yellow solid that is only slightly soluble in water. It can be easily detected by high performance liquid chromatography. With these effects in mind, we performed a randomized, double-blind isoflurane-sparing study in 64 healthy surgical patients between the ages of 18 and $70 \mathrm{yr}$, who were given pentamorphone $(0.75$ $\mu \mathrm{g} \cdot \mathrm{kg}^{-1}$ or $\left.1 \mu \mathrm{g} \cdot \mathrm{kg}^{-1}\right)$ or fentanyl $\left(5 \mu \mathrm{g} \cdot \mathrm{kg}^{-1}\right.$ or 7.5 $\left.\mu \mathrm{g} \cdot \mathrm{kg}^{-1}\right)$ as the analgesic during general anaesthesia for elective procedures of at least $60 \mathrm{~min}$ duration. Anaesthetic depth can often be ascertained from patients' haemodynamic responses and the need for analgesics. Therefore, we compared the haemodynamic profiles and the supplemental dose requirements of patients given fentanyl with those given pentamorphone.

\section{Methods}

After protocol approval by the Human Subjects Review Committee, all patients underwent routine preoperative physical examination and medical history. Patients were excluded from the study if they (1) were undergoing craniotomies, major surgical procedures involving the central nervous system, or open thoracic surgical procedures; (2) were $<18$ yr old; (3) had a haematocrit of $<25 \%$; (4) had an oral temperature $<35^{\circ} \mathrm{C}$ or $>37.5^{\circ} \mathrm{C}$; (5) had a personal or family history of malignant hyperthermia; (6) had a history of unusual reaction or sensitivity to opioid analgesics or anaesthetics; (7) were chronically using drugs known to affect anaesthetic requirement; (8) had angina pectoris or myocardial infarction within the past six months; or (9) were pregnant or breast-feeding. 
TABLE I Demographics

\begin{tabular}{lcccc}
\hline & $5 \mu g \cdot \mathrm{kg}^{-1} \mathrm{~F}$ & $7.5 \mu \mathrm{g} \cdot \mathrm{kg}^{-1} \mathrm{~F}$ & $0.75 \mu \mathrm{g} \cdot \mathrm{kg}^{-1} P$ & $1 \mu \mathrm{g} \cdot \mathrm{kg}^{-1} P$ \\
\hline$n$ & 16 & 16 & 16 & 16 \\
ASA Class I & 5 & 7 & 5 & 6 \\
ASA Class II & 11 & 9 & 11 & 10 \\
Surgical types & & & & \\
- Orthopaedic & 6 & 5 & 5 & 5 \\
- Intraabdominal, laparotomy & 5 & 3 & 5 & 4 \\
- Intrabdominal, laparoscopic & 1 & 1 & 2 & 3 \\
- Other (urology, gynaecology, & & & & \\
ENT) & 4 & 5 & 4 & 6 \\
Age (yr) & $40 \pm 15$ & $34 \pm 14$ & $38 \pm 15$ & $42 \pm 15$ \\
Weight (kg) & $74 \pm 12$ & $69 \pm 11$ & $72 \pm 16$ & $77 \pm 18$ \\
Height (cm) & $168 \pm 10$ & $171 \pm 12$ & $169 \pm 11$ & $168 \pm 13$ \\
Body Surface Area (m) & $1.8 \pm 0.2$ & $1.8 \pm 0.2$ & $1.8 \pm 0.2$ & $1.9 \pm 0.3$ \\
Duration of surgery (min) & $115 \pm 51$ & $138 \pm 59$ & $114 \pm 48$ & $103 \pm 43$ \\
Duration of anaesthesia (min) & $136 \pm 53$ & $155 \pm 54$ & $141 \pm 53$ & $125 \pm 45$ \\
\hline
\end{tabular}

Values are mean \pm standard deviations or counts

Abbreviations: F - fentanyl; P - pentamorphone.

No patient received any sedative or analgesic medication before entering the operating room. After preoxygenation, a total of 64 ASA class I and II patients with written consent were randomized into four equal groups to receive a loading dose of $0.75 \mu \mathrm{g} \cdot \mathrm{kg}^{-1}$ pentamorphone, $1 \mu \mathrm{g} \cdot \mathrm{kg}^{-1}$ pentamorphone, $5 \mathrm{~d} \mu \mathrm{g} \cdot \mathrm{kg}^{-1}$ fentanyl, or $7.5 \mu \mathrm{g} \cdot \mathrm{kg}^{-1}$ fentanyl prepared by the pharmacy to equal dose volumes of $0.15 \mathrm{ml} \cdot \mathrm{kg}^{-1}$ just before induction of anaesthesia. The choice of opioid was blinded to both the patient and the anaesthetist. Thiopentone was given in a sufficient dose to induce loss of eyelash reflex and was followed by $1.5 \mathrm{mg} \cdot \mathrm{kg}^{-1}$ succinylcholine $i v$ (Table I). Vecuronium, $0.05 \mathrm{mg} \cdot \mathrm{kg}^{-1}$, followed by supplemental boluses of $0.01 \mathrm{mg} \cdot \mathrm{kg}^{-1}$, was administered as required to maintain muscular relaxation (Table I). Using a nerve stimulator positioned over the ulner nerve, relaxation was judged as adequate with the presence of 0 or 1 twitch in response to train-of-four stimulation.

When arterial blood pressure or heart rate was $15 \%$ greater than preoperative baseline levels, supplemental doses of $0.15 \mu \mathrm{g} \cdot \mathrm{kg}^{-1}$ pentamorphone or $1.5 \mu \mathrm{g} \cdot \mathrm{kg}^{-1}$ fentanyl prepared by the pharmacy to equal dose volumes of $0.03 \mathrm{ml} \cdot \mathrm{kg}^{-1}$ were administered at five-minute intervals. Isoflurane could then be administered in response to elevations in blood pressure if the patient's response was deemed inadequate after four supplemental doses of opioid. Dosing of volatile anaesthetic progressed incrementally with increases of up to $0.5 \%$ at five-minute intervals to a maximum of $1.5 \%$ (calibrated vaporizer setting). If these supplemental doses of opioid analgesic and changes in isoflurane level were insufficient to control increased heart rate or blood pressure, a rescue bolus of up to $10 \mathrm{mg}$ labetolol could be administered at five- minute intervals until heart rate or blood pressure returned to within $15 \%$ of preoperative baseline levels.

Ventilation was adjusted to maintain a $\mathrm{PETCO}_{2}$ between 30 and $40 \mathrm{mmHg}$ as measured by capnography (model 78345A; Hewlett-Packard, Andover, MA) with a gas mixture of $70 / 30 \% \mathrm{~N}_{2} \mathrm{O} / \mathrm{O}_{2}$. We recorded the following haemodynamic variables: heart rate and systolic, diastolic, and mean arterial pressure using a Dinamap blood pressure monitor with printer (model 1846SX/P, Critikon, Inc. Tampa, FL). Haemodynamic variables were recorded at baseline, induction and then once a minute for three minutes, ten minutes before incision and at two-minute intervals until incision, incision and every minute for five minutes, and finally every $15 \mathrm{~min}$ until $80 \mathrm{~min}$ after incision. In addition, recovery variables, nausea, vomiting, respiratory rate, need for antiemetics, or need for analgesics were noted. In the recovery room, droperidol was administered only to treat nausea and vomiting.

Statistical Analysis System, Inc. (SAS Raleigh, NC) computer programmes were used to perform statistical analysis. Haemodynamic, demographic, and drug dose data were analyzed using standard tests (Bartlett's test and Shapiro and Wilk's W-test) to determine whether deviations from normal distributions and homogeneity of variance were present. None was found, permitting use of two-way analysis of variance of each haemodynamic variable to detect significant interactions between the factors patient group and time. Only if an interaction was found were post hoc analyses of variance for repeated measures (ANOVA) with Duncan's multiple range tests used to assess the significance of the results over time and among patient groups. Based on haemodynamic 
TABLE II Anaesthesia maintenance

\begin{tabular}{|c|c|c|c|c|}
\hline & $5 \mu g \cdot k^{-l} F$ & $7.5 \mu \mathrm{g} \cdot \mathrm{kg}^{-1} \mathrm{~F}$ & $0.75 \mu \mathrm{g} \cdot \mathrm{kg}^{-1} \mathrm{P}$ & $l \mu g \cdot k g^{-1} P$ \\
\hline $\begin{array}{l}0.03 \mathrm{ml} \cdot \mathrm{kg}^{-1} \text { supplemental opioid } \\
\text { analgesic doses given }(n)\end{array}$ & 43 & 20 & 22 & 21 \\
\hline $\begin{array}{l}\text { Patients requiring supplemental } \\
\text { opioid analgesic doses }(n)\end{array}$ & 15 & 10 & 14 & 13 \\
\hline Patients requiring isoflurane $(n)$ & 16 & 16 & 14 & 15 \\
\hline Patients requiring labetolol $(n)$ & 2 & 1 & 2 & 2 \\
\hline $\begin{array}{l}\text { Time from induction to when } \\
\text { isoflurane was given (min) }\end{array}$ & $12 \pm 16$ & $12 \pm 17$ & $37 \pm 10^{*}$ & $43 \pm 26^{*}$ \\
\hline $\begin{array}{l}\text { Duration isoflurane administered } \\
(\mathrm{min})\end{array}$ & $104 \pm 45$ & $104 \pm 50$ & $25 \pm 24^{*}$ & $22 \pm 15^{*}$ \\
\hline $\begin{array}{l}\text { Duration isoflurane as a \% of } \\
\text { duration of anaesthesia }(\%)\end{array}$ & $77 \pm 14$ & $68 \pm 22$ & $18 \pm 14^{*}$ & $18 \pm 11^{*}$ \\
\hline Peak isoflurane concentration (\%) & $1.5 \pm 0.3$ & $1.1 \pm 0.5$ & $1.1 \pm 0.7$ & $0.9 \pm 0.5^{*}$ \\
\hline MAC min isoflurane (min) & $49 \pm 31$ & $58 \pm 28$ & $32 \pm 30$ & $33 \pm 26$ \\
\hline Total labetolol administered (mg) & $10 \pm 5$ & 5 & $15 \pm 5$ & $8 \pm 3$ \\
\hline Amount of vecuronium (mg) & $7 \pm 5$ & $9 \pm 4$ & $6 \pm 5$ & $8 \pm 5$ \\
\hline Amount of thiopentone $\left(\mathrm{mg} \cdot \mathrm{kg}^{-1}\right)$ & $3.6 \pm 0.4$ & $3.8 \pm 0.5$ & $3.7 \pm 0.5$ & $3.8 \pm 0.4$ \\
\hline
\end{tabular}

Values are mean \pm standard deviations or counts.

Abbreviations: F - fentanyl; P - pentamorphone.

$* P<0.05$ versus $5 \mu \mathrm{g} \cdot \mathrm{kg}^{-1}$ fentanyl.

baseline values, a power curve at an $\alpha=0.05$ level of significance and for four patient groups of 15 subjects was used to estimate the detectable difference $(\delta)$ with $90 \%$ power. ${ }^{9}$ The minimal difference $(\delta)$ in haemodynamic means detectable among patient treatment groups was $\geq 25 \%$ of their baseline haemodynamic means. Therefore, differences in haemodynamic means less than $25 \%$ of their baseline value were not detectable using our sample size. One-way ANOVAs were used to compare demographic, peak isoflurane concentration, duration of isoflurane as a percent of duration of anaesthesia, and drug dose data among the patient groups using the Bonferroni method to correct for the ten multiple comparisons. Duration time and $\mathrm{MAC}$ min data were compared among patient groups using the distribution-free Kruskal-Wallis rank sum statistic using the Bonferroni method to correct for the six multiple comparisons. Categorical comparisons were analyzed using the nonparametric Mantel-Haenszel chi-squared tests using the Bonferroni method to correct for the fifteen multiple comparisons. Differences were considered statistically significant if $P<0.05$. Values are reported as means with standard deviations or counts.

\section{Results}

No differences in demographic data, duration of surgery or anaesthesia, or types of surgery were noted among the four study groups (Table I). No differences in thiopentone dose to loss of eyelash reflex or vecuronium requirement were noted among the four study groups (Table II). No patient experienced recall or change in respiratory rate (Table III). Both analgesics were clinically satisfac- tory, as the haemodynamic profiles of the four groups showed no differences among heart rate (Figure 2), mean arterial pressure (Figure 3), systolic arterial pressure (Figure 4), or diastolic arterial pressure (Figure 5).

Only one patient in the $5 \mu \mathrm{g} \cdot \mathrm{kg}^{-1}$ fentanyl group did not require supplemental doses of opioid, with the remaining 15 patients receiving a mean number of $2.7 \pm$ 1.5 supplemental doses. Six patients in the $7.5 \mu \mathrm{g} \cdot \mathrm{kg}^{-1}$ fentanyl group did not require supplemental doses of opioid analgesic, with the remaining ten patients receiving $3.8 \pm 2.4$ supplemental doses. Two patients in the 0.75 $\mu \mathrm{g} \cdot \mathrm{kg}^{-1}$ pentamorphone group did not require supplemental doses of opioid analgesic, with the remaining 14 patients receiving $3.2 \pm 1.9$ supplemental doses. Three patients in the $1.0 \mu \mathrm{g} \cdot \mathrm{kg}^{-1}$ pentamorphone group did not require supplemental doses of opioid analgesic, with the remaining 13 patients receiving $3.1 \pm 1.8$ supplemental doses. There was no difference among the four study groups in the total number or the mean number of supplemental doses (Table II).

Two patients in the $5 \mu \mathrm{g} \cdot \mathrm{kg}^{-1}$ fentanyl group (mean total dose, $10 \pm 5 \mathrm{mg}$ ), one patient in the $7.5 \mu \mathrm{g} \cdot \mathrm{kg}^{-1}$ fentanyl group (mean total dose $5 \mathrm{mg}$ ), two patients in the $0.75 \mu \mathrm{g} \cdot \mathrm{kg}^{-1}$ pentamorphone group (mean total dose mean $15 \pm 5 \mathrm{mg}$ ), and two patients in the $1.0 \mu \mathrm{g} \cdot \mathrm{kg}^{-1}$ pentamorphone group received labetolol (mean total dose $8 \pm 3 \mathrm{mg}$ ). There was no difference in the number of patients requiring labetolol or in the amounts of labetolol administered (Table II).

When considering the use of isoflurane, the pentamorphone groups differed from the fentanyl groups. $\mathrm{Pa}$ - 
TABLE III Recovery from anaesthesia

\begin{tabular}{|c|c|c|c|c|}
\hline & $5 \mu g \cdot \mathrm{kg}^{-1} \mathrm{~F}$ & $7.5 \mu \mathrm{g} \cdot \mathrm{kg}^{-1} \mathrm{~F}$ & $0.75 \mu g \cdot \mathrm{kg}^{-1} P$ & $I \mu g \cdot k^{-l} P$ \\
\hline \multicolumn{5}{|l|}{ Patients with postoperative } \\
\hline nausea $(n)$ & 4 & 6 & 2 & 5 \\
\hline Patients experiencing recall $(n)$ & 0 & 0 & 0 & 0 \\
\hline \multicolumn{5}{|l|}{ Patients with postoperative } \\
\hline vomiting $(n)$ & 4 & 3 & 2 & 2 \\
\hline $\begin{array}{l}\text { Patients receiving } 0.625 \mathrm{mg} \text { of } \\
\text { droperidol }(n)\end{array}$ & 3 & 2 & 1 & 1 \\
\hline $\begin{array}{l}\text { Patients requiring postoperative } \\
\text { morphine }(n)\end{array}$ & 5 & 9 & 9 & 6 \\
\hline $\begin{array}{l}\text { Time from end of } \mathrm{N}_{2} \mathrm{O} \text { to } \\
\text { extubation (min) }\end{array}$ & $5 \pm 6$ & $9 \pm 8$ & $4 \pm 2$ & $11 \pm 17$ \\
\hline Postoperative morphine dose (mg) & $6.5 \pm 6.0$ & $4.8 \pm 2.4$ & $7.1 \pm 3.6$ & $3.7 \pm 2.0$ \\
\hline
\end{tabular}

Values are mean \pm standard deviations or counts.

Abbreviations: F - fentanyl; P - pentamorphone.

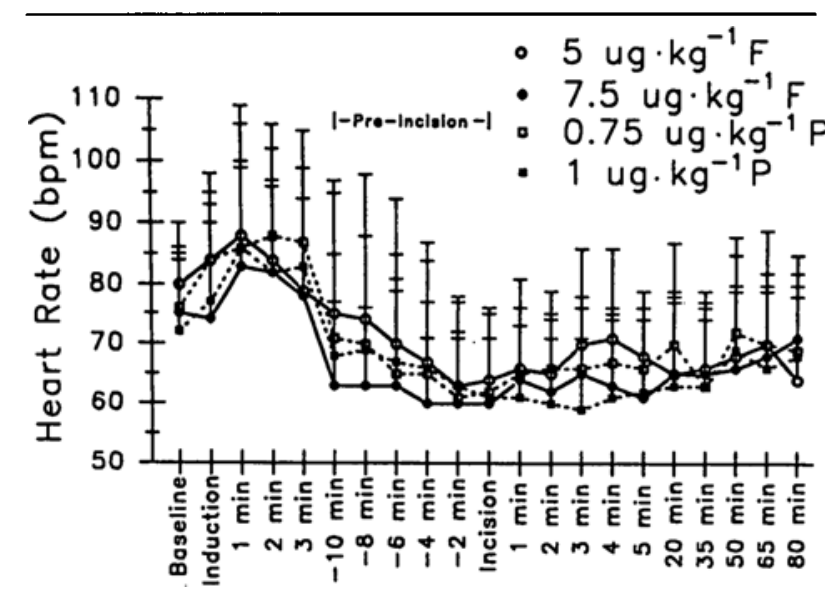

FIGURE 2 Comparison of heart rates (bpm). The data are displayed as means and standard deviations. The fentanyl patients' data are shown as solid lines while pentamorphone patients' data are shown as dashed lines.

tients receiving $0.75 \mu \mathrm{g} \cdot \mathrm{kg}^{-1}$ pentamorphone did not require isoflurane supplementation until $37 \pm 10 \mathrm{~min}$ after the start of anaesthesia, and patients receiving $1 \mu \mathrm{g} \cdot \mathrm{kg}^{-1}$ pentamorphone did not need isoflurane supplementation until $43 \pm 26 \mathrm{~min}$ (Table II). However, the patients given either 5 or $7.5 \mu \mathrm{g} \cdot \mathrm{kg}^{-1}$ fentanyl required isoflurane sooner (12 \pm 16 and $12 \pm 17 \mathrm{~min}$, respectively) $(P<$ 0.05 ). The total time of isoflurane administration for the 5 or $7.5 \mu \mathrm{g} \cdot \mathrm{kg}^{-1}$ fentanyl groups was longer (104 \pm 45 and $104 \pm 50 \mathrm{~min}$, respectively) than either the 0.75 or $1 \mu \mathrm{g} \cdot \mathrm{kg}^{-1}$ pentamorphone groups $(25 \pm 24$ and 22 $\pm 15 \mathrm{~min}$, respectively) $(P<0.05)$. No differences in MAC min of isoflurane were noted among the four study groups (Table II).

Recovery from anaesthesia was satisfactory for all four

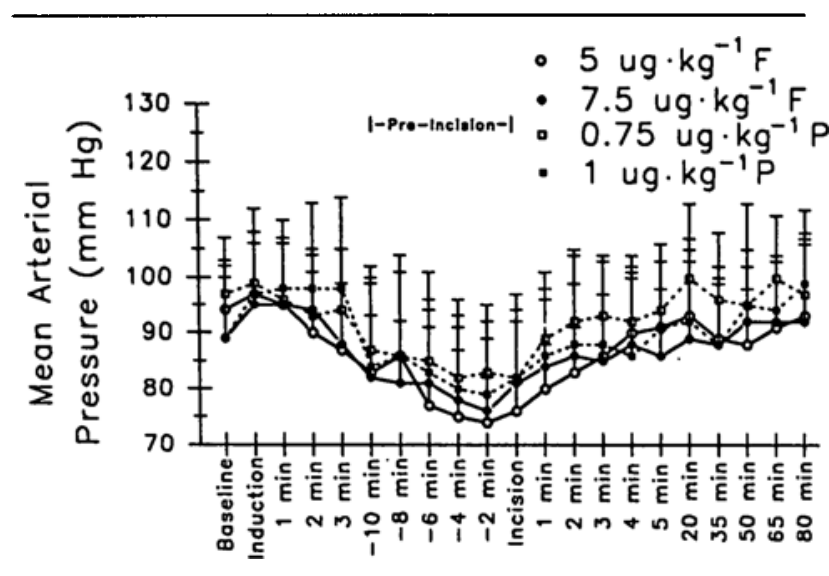

FIGURE 3 Comparison of mean arterial pressures $(\mathrm{mmHg})$. The data are displayed as means and standard deviations. The fentanyl patients' data are shown as solid lines while pentamorphone patients' data are shown as dashed lines.

study groups (Table III). The time from the end of $\mathrm{N}_{2} \mathrm{O}$ administration to extubation was shortest for the 0.75 $\mu \mathrm{g} \cdot \mathrm{kg}^{-1}$ pentamorphone group. There was no difference in the use or dose of postoperative morphine among the four groups.

\section{Discussion}

The primary goal in the development of any new analgesic is increasing effectiveness against pain in a dosedependent manner without haemodynamic or respiratory depression. Ideally, any new analgesic should provide an advantage over previously available drugs. The haemodynamic stability we found with pentamorphone is supported by a similar study with balanced anaesthesia. ${ }^{13}$ Our study demonstrated that pentamorphone's advantage over fentanyl was in the lower requirement for inhalational 


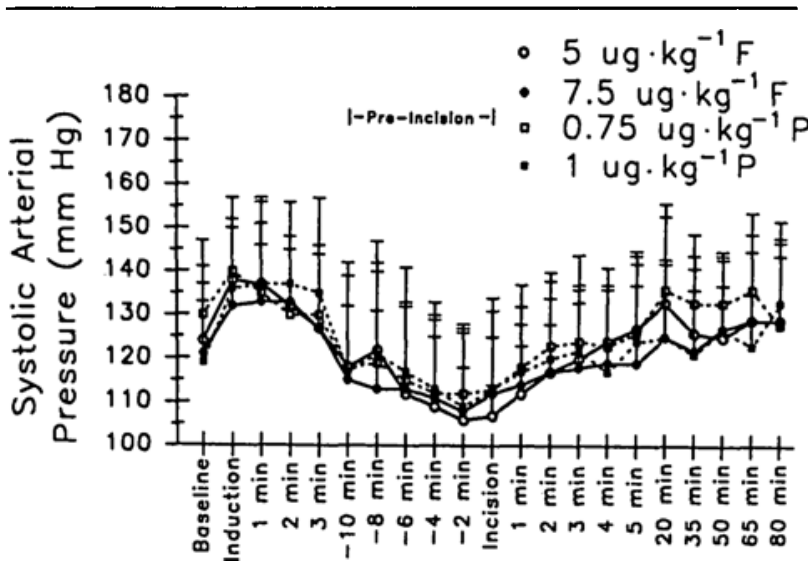

FIGURE 4 Comparison of mean systolic arterial pressures $(\mathrm{mmHg})$. The data are displayed as means and standard deviations. The fentanyl patients' data are shown as solid lines while pentamorphone patients' data are shown as dashed lines.

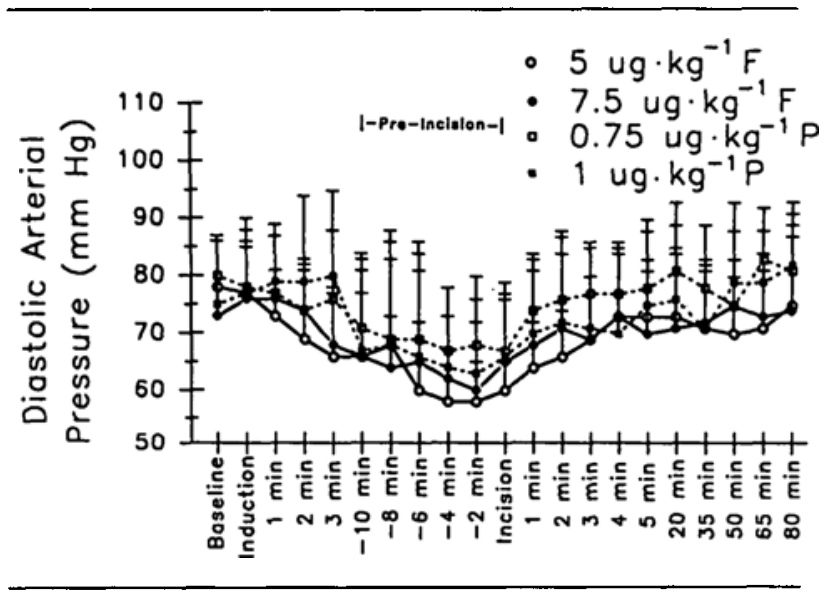

FIGURE 5 Comparison of mean diastolic arterial pressures $(\mathrm{mmHg})$. The data are displayed as means and standard deviations. The fentanyl patients' data are shown as solid lines while pentamorphone patients' data are shown as dashed lines.

agent in a balanced anaesthesia technique. The most apparent differences in inhaled anaesthetic requirements were the duration of isoflurane use and interval of induction to initiation of volatile anaesthetic (Table II). Lowdon et al. ${ }^{10}$ also demonstrated an increased interval from induction to initiation of volatile anaesthetic with the use of pentamorphone compared with fentanyl. We feel that pentamorphone was responsible for these differences in volatile anaesthetic use because we found no differences in recovery time, number of patients requiring labetolol, or number of patients requiring supplemental intraoperative opioid analgesic doses. Although the mean difference in total MAC min was not found to be different among the fentanyl and pentamorphone groups, this was most likely a result of our sample size. Individual dif- ferences were apparent in length of MAC anaesthesia as well as the amount of inhaled anaesthetic requirement. The drug group's mean difference of approximately 20 MAC min was not significant because the standard deviations were all over $25 \mathrm{MAC}$ min. Therefore more studies at higher doses are indicated to delineate the actual effective dose of pentamorphone.

Although pentamorphone has been shown to depress ventilatory responses to hypoxia and hypercapnia, "we found that pentamorphone demonstrated potent analgesic effects and effective blunting of the haemodynamic response to surgery, without increased incidence of respiratory rate change or perioperative haemodynamic complication. We found patients tolerated pentamorphone well and it appears to offer isoflurane-sparing advantages over fentanyl in general anaesthesia.

\section{Acknowledgments}

We would like to express our appreciation to the Samuel J. Roessler Memorial Medical Research Scholarship for financial support of the medical students Ernst W. Lisek, Martin J. Kungl, Lisa Bohman Egbert, Brad S. Efaw, Brian S. Myers, Todd N. Cardwell, Caroline J. Caine, and Bradley D. Egbert. In addition, we wish to acknowledge Anaquest Inc. for their support in this study.

\section{References}

1 Glass PSA, Doherty MA, Helms MJ. Relative analgesic potency of pentamorphone and fentanyl. Anesthesiology 1989; 71: A761.

2 Parker RK, Holtmann B, White PF. Initial clinical evaluation of pentamorphone: a new opioid analgesic. Anesth Analg 1990; 70: S298.

3 Wong $H Y$, Parker RK, Fragen $R$, White PF. Pentamorphone for management of postoperative pain. Anesth Analg 1991; 72: 656-60.

4 Glass PSA, Camporesi EM, Shafron D, Quill T, Reves JG. Evaluation of pentamorphone in humans: a new potent opiate. Anesth Analg 1989; 68: 302-7.

5 Ginsberg B, Muir M, Damask M, Quill TJ, Glass PSA. Assessment of the analgesic efficacy of pentamorphone to morphine. Anesthesiology 1990; 73: A836.

6 Ho WM, Ashburn MA, Liu WS, et al. Cardiovascular effects of large doses of pentamorphone in the dog. J Cardiothorac Vasc Anesth 1990; 4: 326-31.

7 Falinski BA, Sebel PS, Hug CC Jr, Klochany A. Pharmacodynamics of pentamorphone during coronary artery bypass grafting in humans. $\mathbf{J}$ Cardiothorac Vasc Anesth 1992; 6: 168-72.

8 Rudo FG, Wynn RL, Ossipov M, et al. Antinociceptive activity of pentamorphone, a 14-beta-aminomorphinone derivative, compared to fentanyl and morphine. Anesth Analg 1989; 69: 450-6. 
9 Howie MB, McSweeney TD, Lingam RP, Maschke SP. A comparison of fentanyl- $\mathrm{O}_{2}$ and sufentanil- $\mathrm{O}_{2}$ for cardiac anesthesia. Anesth Analg 1985; 64: 877-87.

10 Lowdon JD, Sebel PS, Murphy MR. Pentamorphone in balanced anesthesia: comparison with fentanyl. Anesthesiology 1989; 71: A225.

11 Afifi MS, Glass PSA, Cohen NA, Shook JE, Camporesi $E M$. Depression of ventilatory responses to hypoxia and hypercapnia after pentamorphone. Anesth Analg 1990; 71 : 377-83. 